\title{
INCREASE IN URINE OSMOLALITY, SODIUM, POTASSSIUM, AND UREA NITROGEN IN VERY PREMATURE NEONATES WITH OPEN DUCTUS ARTERIOSUS
}

\author{
A. Sellmer ${ }^{1,2}$, J. Bjerre $^{1}$, B.H. Bech ${ }^{3}$, V.E. Hjortdal ${ }^{4}$, T.B. Henriksen ${ }^{1,2}$ \\ ${ }^{1}$ Department of Paediatrics, ${ }^{2}$ Perinatal Epidemiology Research Unit, Aarhus University Hospital, ${ }^{3}$ School of \\ Public Health, Department of Epidemiology, Aarhus University, ${ }^{4}$ Department of Thoracic Surgery, Aarhus \\ University Hospital, Aarhus, Denmark
}

Background and aims: To investigate if urine osmolality, sodium, potassium, and urea levels on day four are associated with an open ductus arteriosus (DA) on day seven in neonates with gestational age (GA) below 32 weeks.

Methods: Fifty five newborns were recruited (January - October 2011). Echocardiography was performed on day four and seven of life. Diameter of DA (dDA) and left atrial-aorta ratio (LAAo) were evaluated. Urine osmolality, sodium, potassium, and urea nitrogen were analysed in 24 hour urinary samples collected day four. Medians are presented with 25 and 75 centiles.

Results: DA was open day four in 28 (51\%) of neonates and in 23 day seven. On day four dDA was $1.8 \mathrm{~mm}$ (1.2-2.3) and LAAo 1.5 (1.2-1.7). Neonates with an open DA day seven had a higher median urine osmolality on day four $321 \mathrm{mOsm} / \mathrm{kg}$ (220-413) compared to neonates with a closed DA $196 \mathrm{mOsm} / \mathrm{kg}$ $(144-262)(\mathrm{p}<0.05)$. Increased median level of urine sodium $(75 \mathrm{mmol} / 1(55-103) \mathrm{vs} .52 \mathrm{mmol} / 1(31-64), \mathrm{p}<$ $0.05)$, urine potassium $(17 \mathrm{mmol} / \mathrm{l}(12-21)$ vs. $12 \mathrm{mmol} / \mathrm{l}(8-17), \mathrm{p}=0.05)$, and urine urea $(53 \mathrm{mmol} / \mathrm{l}(44-78)$ vs. $41 \mathrm{mmol} / 1(32-52), \mathrm{p}<0.05)$ were found.

Conclusions: Half of all very preterm neonates had an open DA on day four and $42 \%$ on day seven. We found that urine osmolality, sodium, potassium, and urea were increased on day four in neonates with an open DA on day seven. Further analyses are done to characterize renal water and electrolyte handling in neonates with DA. 